\title{
Coronary Sinus Ablation Is a Key Player Substrate in Recurrence of Persistent Atrial Fibrillation
}

\author{
Naseer Ahmed ${ }^{\mathrm{a}, \mathrm{b}}$ Shahida Perveen ${ }^{\mathrm{c}}$ Adeela Mehmood $^{\mathrm{d}}$ Gulab Fatima Rani $^{\mathrm{e}}$ \\ Giulio Molon ${ }^{b}$ \\ ${ }^{a}$ Department of Biological and Biomedical Sciences, The Aga Khan University, Karachi, Pakistan; ${ }^{b}$ Department of \\ Cardiology, IRCCS Sacro Cuore Don Calabria Hospital, Negrar, Verona, Italy; ' Department of Medicine, Foundation \\ University Islamabad, Islamabad, Pakistan; dDepartment of Pharmacology, Liaqat National Medical College, Karachi,

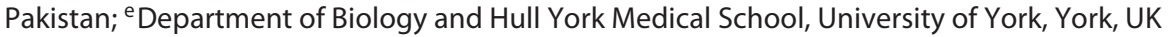

\section{Keywords}

Atrial fibrillation · Coronary sinus · Radiofrequency

ablation $\cdot$ Complex fractionated atrial electrograms

\begin{abstract}
Atrial fibrillation (AF) is the most frequent atrial arrhythmia. During the last few decades, owing to numerous advancements in the field of electrophysiology, we reached satisfactory outcomes for paroxysmal AF with the help of ablation procedures. But the most challenging type is still persistent $A F$. The recurrence rate of $A F$ in patients with persistent $A F$ is very high, which shows the inadequacy of pulmonary vein isolation (PVI). Over the last few decades, we have been trying to gain insight into AF mechanisms, and have come to the conclusion that there must be some triggers and substrates other than pulmonary veins. According to many studies, PVI alone is not enough to deal with persistent AF. The purpose of our review is to summarize updates and to clarify the role of coronary sinus (CS) in AF induction and propaga-
\end{abstract}

An abstract of this study has been presented at 12th International Congress of Update in Cardiology and Cardiovascular Surgery, Antalya, March 2016, and published in American Journal of Cardiology (supplemental issue).

\section{KARGER}

(c) 2019 S. Karger AG, Basel

E-Mail karger@karger.com

www.karger.com/crd tion. This review will provide updated knowledge on developmental, histological, and macroscopic anatomical aspects of CS with its role as arrhythmogenic substrate. This review will also inform readers about application of CS in other electrophysiological procedures.

(c) 2019 S. Karger AG, Basel

\section{Introduction}

The coronary sinus (CS) is the largest cardiac venomuscular structure draining most of cardiac venous blood into the right atrium. The CS musculature is an extension of atrial myocardial fibers [1] providing not only an anatomical bridge between atria but an electrical connection as well [2]. For a long time, CS has only been considered a venous structure, but recently its role in the pathophysiology of atrial tachyarrhythmias has been recognized [3-10]. Knecht et al. [10] showed that focal tachyarrhythmia originates from CS and ablation within the CS eliminates the tachycardia.
Giulio Molon, MD, FESC and FACC

Department of Cardiology

IRCCS Sacro Cuore Don Calabria Hospital

IT-37023, Negrar, Verona (Italy)

E-Mail elettrofisiologo@gmail.com

Naseer Ahmed, MBBS, PhD

Department of Biological and Biomedical Sciences

Aga Khan University Hospital

Stadium Road, Karachi (Pakistan)

E-Mail dr.naseer99@gmail.com 
Fig. 1. a Posterior view of the heart showing the coronary sinus (CS) connecting the right (RA) and left (LA) atrium. b Posterior aspect of the heart. Yellow arrow demonstrates the extension of atrial fibers on CS. RAA, right atrial appendage; RV, right ventricle; LV, left ventricle; dCS, distal coronary sinus, pCS, proximal coronary sinus; SCV, superior vena cava [16].

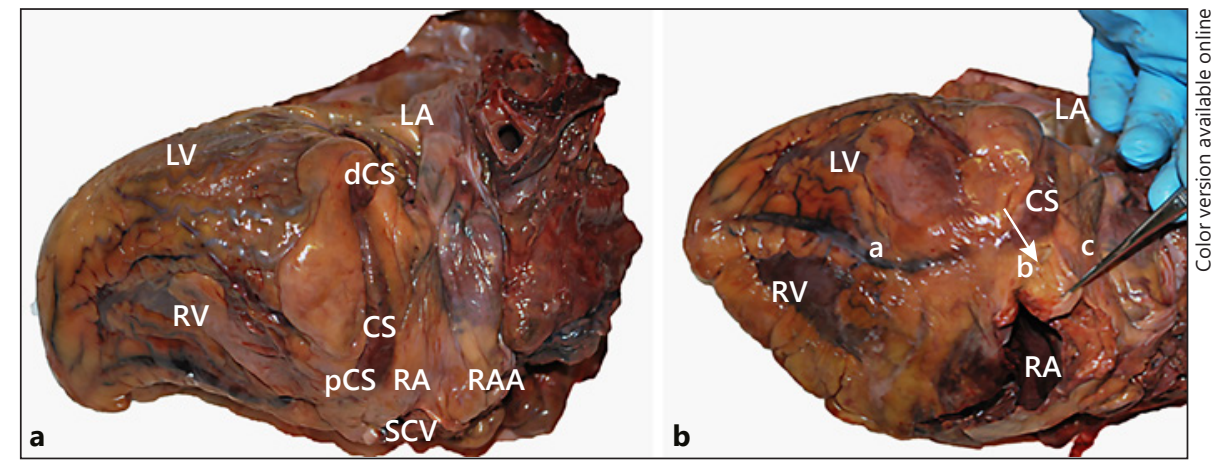

Catheter ablation of CS, at the endocardial and epicardial region, increases atrial fibrillation (AF) cycle length that is an indicator of AF termination [3]. The CS also provides percutaneous epicardial access for ablation, even in patients with previously failed endocardial radiofrequency (RF) ablation, which helps improve the outcome [11]. AF is a rapidly growing problem in routine clinical practice. To cope with this expanding health issue first, we need to know the exact substrate for AF. This review is an outline of the knowledge about relation of pathophysiology, mechanism of initiation, maintenance, and recurrence of AF with CS.

\section{Macroscopic Anatomy of CS}

The CS has a key role in myocardial venous drainage. About $60 \%$ of drainage is performed by CS, the remaining $40 \%$ by anterior and small cardiac veins. The CS receives four major tributaries: the great, middle, small, and posterior cardiac veins; the other two groups include anterior veins of the right ventricle also called anterior cardiac veins and the smallest group of cardiac veins named Thebesian veins that drain directly into the tributaries of the greater and smaller cardiac veins [12-14]. The CS is the continuation of the great cardiac vein that runs posteriorly in the left atrioventricular groove (Fig. 1). The anterior wall of the left ventricle and the interventricular septum are drained by the tributaries of the anterior interventricular vein, which collectively form the great cardiac vein on the annulus $[4,7,13,14]$. The great cardiac vein joins the main posterior lateral vein to form CS. Remaining parts of the heart are drained by small cardiac veins into the ostium of CS [7]. Anatomically, CS starts from the ostium in the right atrium, positioned below the foramen ovale and above the inferior vena cava, and ends as a great cardiac vein [15] (Fig. 1).
CS lies in the coronary groove that is located on the diaphragmatic part of the heart (Fig. 1). Gray's anatomy describes "the coronary sinus as a wide venous channel, about $2.25 \mathrm{~cm}$ in length, situated in the posterior part of atrioventricular sulcus of the heart, usually covered by muscular fibers from the left atrium" and it has been considered as a part of the venous system for long time. In 2004, Barceló et al. [17] demonstrated that it is not a usual venous structure like other cardiac veins and also hypothesized that CS is a fifth small chamber of the heart with atrial myocardial characteristics [17].

\section{Developmental Anatomy}

Embryologically, the CS originates from the differentiation of the left sinus horn that is vital for the development of the complete venous system of the heart [18, 19]. Maturity and sexual dimorphism of the CS during antenatal period have an impact on its histological and electrophysiological features [20]. The CS and oblique vein of Marshall are both derivatives of sinus venosus. The muscular tissue around CS can be right atrial (RA) myocardial tissue continuation. Some of these muscular sleeve fibers join left atrial (LA) myocardial tissue that makes second most important connection between atria [21]. The proximal two-thirds of the CS have double muscular covering from the embryonic stage [10]. Muscular sheath is a derivative of the left sinus horn with some involvement from developing adjacent LA [21]. This double muscular covering of the CS plays an important role in interatrial connection [22]. The CS anomalies are classified by Mantini et al. [66], e.g. enlargement of CS, absence of CS, atresia of RA CS ostium, and hypoplasia of the CS [23]. These anomalies also affect the electrophysiological characteristics of CS. Ambrose et al. [24] reported the relationship between CS 
ostium enlargement and supraventricular tachycardia in children. CS ablation can be done in patients with AF with CS anomalies even without prior PVs isolation [25].

\section{Histological Features of CS}

Barceló et al. [17] described three discrete layers including endocardium, myocardium, and epicardium similar to those of four cardiac chambers, which makes it different from other cardiac veins. In contrast to veins, the CS contains myocardial tissue, which is a continuation of left atrium muscles $[21,26]$, consisting of striated myofibrils like those of myocardium with intercalated discs; Jan Evangelista Purkyně was probably the first to discover this important fact [27]. On the posterior surface of CS, multiple Purkinje like cells with typical features like clear perinuclear halo, are present near the entrance of oblique Marshall veins [17]. In addition, cells similar to those of sinus node (P cells) with increased quantity of merged connective tissue were also found. Rossi [28] demonstrated that P-like cells were embryologically derived from primitive myocardial cells; the authors described multiple ganglionic neurons below the epicardial layer of the CS on the posterior aspect. Recently, Kugler et al. [29] discovered Purkinje-like cells in the myocardial layer of CS, which may be an important part of the mechanisms for AF initiation and maintenance due their conduction properties.

\section{Clinical Significance of the CS}

The CS is becoming an important subject of investigation in cardiac electrophysiological techniques; mainly, it provides access to the left heart for the implantation of biventricular pacing, epicardial mapping, and ablation techniques. It provides a route through epicardial surface to access atrial and ventricular accessory pathways $[3,30]$. Total occlusion of left circumflex artery during ablation inside the CS can lead to life-threatening arrhythmias [31, 32]. Other complications like sudden cardiac death followed by ventricular fibrillation have been reported [31]. Due to its anatomic and electrophysiological relationship with atria, CS can be used to localize the origin of multifocal atrial tachycardia from either atrium by using electrophysiological mapping, where a high-frequency, higher-amplitude component indicates a near-field potential originating from the myocardial tissue of the CS, and a low-frequency, lower-amplitude component indicates a far-field potential from the activation of the adjacent LA $[33,34]$.

\section{Use of RF Ablation for CS}

$\mathrm{RF}$ is the most common method currently used to ablate into the CS, usually with a three-dimensional anatomic guide system that allows detecting the areas to ablate. RF applications are delivered with maximum power set at 40-45 W and temperature control limited to 55$60^{\circ} \mathrm{C}$ using a standard, nonirrigated, $4-\mathrm{mm}$ tip catheter. Recently, the use of catheters with irrigation and contact force has increased to deliver RF energy with higher efficacy and safety, with the irrigation rate ranging from 10 to $20 \mathrm{~mL} / \mathrm{min}$, maximum power set at $20-25 \mathrm{~W}$ and temperature control limited to $40-50^{\circ} \mathrm{C}$.

\section{Electrophysiological Features}

The CS is a myocardial connection between right and left atria, and participates in simultaneous physiological contractions of both atria $[21,35]$. As mentioned earlier, the muscular sleeve around the proximal $25-50 \mathrm{~mm}$ of its length [35] also connects two atria. These connections may play a role in arrhythmogenesis by acting as a trigger for $\mathrm{AF}$ and by forming a part of reentrant circuit [36]. The amplitude of the CS signal is an indicator of LA scarring, which is thought to be an important mechanism in AF maintenance [37]. The electrophysiological properties inside and outside the coronary ostium are completely different. The way of impulse generation in both areas is also variable. Impulse generation outside the CS does not need any force [38], while CS musculature needs external stimulus, even in response to catecholamines to generate impulse [39]. Action potential in CS is similar to atrial myocytes [39]. Norepinephrine enhances and acetylcholine decreases automaticity of the CS cells during spontaneous diastolic depolarization [39]. Resting potentials in $\mathrm{CS}$ atrial cells are $>-80 \mathrm{mV}$ and also show a plateau phase during repolarization, when the activity is regular. During decreased activity, the action potential also declines to $<-70 \mathrm{mV}$ [39]. Conduction block occurs due to a different nature of tissue, on the outside and inside of CS ostium. Habib et al. [42] showed in their study that CS musculature is capable of spontaneous depolarization and slow conduction, showing intrinsic automaticity $[12$, $40,41]$. Blood flow through CS becomes maximum dur- 
Table 1. Summary of radiofrequency ablation for coronary sinus to treat atrial fibrillation

\begin{tabular}{|c|c|c|c|c|c|}
\hline Pambrun, 2019 [51] & 10 & Persistent AF & $\begin{array}{l}\text { RF with } 3.5-\mathrm{mm} \text { irrigated- } \\
\text { tip catheter, temperature } \\
\text { limited to } 45^{\circ} \mathrm{C} \text {; for each } \\
\text { point, RF energy was } \\
\text { delivered for } 15-20 \mathrm{~s} \text { with } \\
\text { a power output of } 20-25 \\
\text { W }\end{array}$ & n.a. & $100 \%$ at 6 months \\
\hline Fassini, 2005 [52] & Total 187 (CS ablation in 95) & $\begin{array}{l}126 \text { paroxysmal } \\
61 \text { persistent }\end{array}$ & $\begin{array}{l}\text { RF with irrigated-tip } \\
\text { catheter with maximum } \\
\text { power set at } 20 \mathrm{~W}\end{array}$ & $\begin{array}{l}1 \text { transient } \\
\text { ischemic attack } \\
1 \text { cardiac tampon- } \\
\text { ade }\end{array}$ & $71 \%$ at 1 year \\
\hline Oral, 2003 [53] & Total 22 (CS ablation in 9) & 22 paroxysmal & $\begin{array}{l}\mathrm{RF} \text { with standard } 4-\mathrm{mm} \\
\text { tip catheter, with applica- } \\
\text { tions } 30 \mathrm{~s} \text { in duration, } \\
\text { with a target temperature } \\
\text { of } 60^{\circ} \mathrm{C} \text { and maximum } \\
\text { power of } 50 \mathrm{~W}\end{array}$ & n.a. & $82 \%$ at $199 \pm 35$ days \\
\hline Haissaguerre, 2007 [3] & 45 & $\begin{array}{l}15 \text { paroxysmal } \\
30 \text { persistent }\end{array}$ & $\begin{array}{l}\text { RF with irrigated-tip } \\
\text { catheter; power of } 30- \\
40 \mathrm{~W} \text { endocardial; inside } \\
\text { the CS, a maximal power } \\
\text { of } 25 \mathrm{~W} \text {; temperature } \\
\text { limited to } 50^{\circ} \mathrm{C}\end{array}$ & $\begin{array}{l}1 \text { patient cardiac } \\
\text { tamponade, } 1 \\
\text { pulmonary edema }\end{array}$ & $\begin{array}{l}39 \text { patients ( } 12 \text { of } \\
15 \text { ParAF, } 27 \text { of } 30 \\
\text { PerAF) were ar- } \\
\text { rhythmia free at } 10 \\
\text { months }\end{array}$ \\
\hline
\end{tabular}

ing slow ejection and protodiastolic phases of cardiac cycle [21]. CS like other veins has compliance and is not influenced by other regulatory mechanisms of coronary vessels. Habib et al. [42] demonstrated clinical importance of connections between right and left atria which could be a source of arrhythmias, like AF [7, 42].

\section{Role of CS in Inception and Propagation of AF}

In 1907, Erlanger and Blackman [43] explained rhythmogenicity of CS. They cut atria into small slices and observed rhythmicity of those small pieces and interpreted results on an anatomical basis. AF may be triggered by the spontaneous firing of the CS cells $[29,42]$, and the main mechanism of its maintenance is re-entry phenomenon, and CS is involved in this re-entry mechanism as suggested by Morita et al. [45], where CS has an important role in triggering, maintenance, and recurrence of $\mathrm{AF}[36$, 44]. The role of pulmonary veins in AF pathogenesis is well established [46] for paroxysmal AF, but pulmonary vein ablation is not sufficient to treat persistent $A F$. This failure to address persistent AF using pulmonary vein ablation demonstrates an additional re-entry mechanism, probably involvement of CS. Rotter et al. [47] published a case of a 59-year-old patient, who underwent RF catheter ablation (RFCA) of PVIs even with modified substrate ablation including joining superior PVs and anterior mitral annulus. There was clinical improvement, but AF recurrences were evidenced; further mapping showed an independent localized source of AF originating from CS. After CS isolation, there was no more recurrence of AF. CS is the structure observed with focal origin of atrial tachycardia $[48,49]$.

\section{Effects of CS Isolation on AF}

CS is a well-developed interatrial connection. Interruption in the electrical activity of CS may improve the results of RFCA for AF because usually unstable re-entrant circuits appear in CS musculature and its atrial junctions [45]. This was demonstrated by Morita et al. [45] in their RFCA 3-step procedure of CS isolation with conduction monitoring during CS pacing. The first step was circular ablation of CS ostium to block electrical conduction between CS ostium and RA. Then in the second step, a $13.8 \pm 7.5 \mathrm{~mm}$ linear ablation was performed between proximal CS and LA junction. After the first two steps, a connection was still found between distal CS and LA 
junction in 12 tissues. Finally, the third step with a $8.3 \pm$ $2.5 \mathrm{~mm}$ linear lesion was made by RF energy. After the first step of RFCA, RA activation was significantly delayed as before RFCA activation of both atria was direct during CS pacing. After the second step of RFCA, LA and RA activation was significantly delayed leading to a complete block after the third step of RFCA. But after complete isolation of CS, there were still some electrical signals from distal CS to LA junction associated with the vein of Marshall [45]. Recently, Yin et al. [50] reported that the frequency of AF was significantly higher in proximal CS and a lower distal CS/proximal CS ratio $(<67 \%)$ indicates better long-term outcome. Pambrun et al. [51] confirmed these data, showing that RF ablation of epicardium muscular bundles in CS is an important step to achieve the resolution of AF in a short time follow-up as mentioned in Table 1.

In this review, as well as the study by Mainigi et al. [54], it was suggested that CS might be an arrhythmogenic substrate and play a role in AF recurrence in post PVI patients. Di Biase et al. [55] recommend that for treatment of persistent $\mathrm{AF}$, ablation of nonpulmonary vein triggers of AF including CS in addition to PVI, improves the longterm outcome of RFCA by decreasing the recurrences. Sanders et al. [56] have reported a successful electrical disconnection of CS from RA and LA where focal ablation inside CS was not successful.

\section{Role of Complex Fractionated Atrial Electrograms in Termination of AF and Its Prevalence in CS}

CS is recognized as a common area for fractionated electrograms and used as a target for ablation in persistent AF $[5,41,57,58]$. Multiple factors are involved in the pathogenesis and recognition of AF substrate; the most common indicator is complex fractionated atrial electrograms (CFAEs) with short AF cycle length [58]. In 1997, Konings et al. [59] have for the first time explained fractionated electrograms, showing slow conduction areas in AF patients. Nademanee et al. [40] have for the first time demonstrated that CFAEs could be an ideal target for ablations in patients with AF. The targeted ablation of CFAEs has a great impact on long-term maintenance of the sinus rhythm in spite of LA enlargement [60]. In addition to PV ablation, CFAE ablation significantly improves results in persistent AF [61]. Forleo et al. [62] described the highest prevalence of CFAEs in distal CS, while Teh et al. [58] have demonstrated in their study that prevalence of CFAEs and short AF cycle length was high- er in proximal CS, whereas the study by Boles et al. [63] suggested their presence in both the proximal and distal CS depending on whether they originated from RA or LA. Yoshida et al. [30] have suggested that the frequency and complexity of CS CFAEs might indicate the presence of AF sources and that dominant frequencies decrease within the CS might predict procedural success. Boles et al. [63] reported that CS CFAEs can predict the recurrence of AF after the ablation procedure. In conclusion, the high prevalence of CFAEs in CS and the good impact of CFAE target ablation on persistent AF suggest a role of $\mathrm{CS}$ in AF recurrence even after PV isolation.

\section{Discussion}

$\mathrm{AF}$ is the most common atrial arrhythmia in humans [46], which is increasing exponentially. The incidence increases with the advancing age. The PVs are common, and important structures are involved in the initiation of $\mathrm{AF}$ [46]. Since the last decade, one of the burning questions has been, "What is the underlying mechanism of AF or which part of the heart is responsible for initiation and maintenance of AF, especially recurrence after PV ablation." To achieve successful results in chronic AF, emphasis on nonpulmonary triggers is of utmost importance [55]. This is becoming very challenging these days especially with the arrival of novel ablation therapies in the field of electrophysiology, with high hopes of recovery from AF. Initially, these new ablation techniques showed promising results; however, after a short period physicians realized that even PV ablation was not very successful for persistent AF. This indicates that PVs are not the right ablation target for persistent AF. In order to find the right target for ablation, we have tried to systematically analyze the way of mapping and isolating PVs. New techniques of mapping the accessory pathways have allowed us to find answers to our question of failure to achieve significant outcomes with RF ablation. Several studies have provided sufficient evidence about the role of CS in AF maintenance, due to its connections with RA and LA. There is also embryological evidence that CS is involved in conduction and may be the origin of macro re-entrant circuits to maintain AF, even after PVIs. Interesting data come from CFAEs records, which demonstrate good clinical outcome after ablation of CFAEs to terminate persistent AF [64]. Ablation of drivers in CFAE has been found to be sufficient to terminate persistent $\mathrm{AF}$ in the majority of patients [65]. As reported earlier, CFAEs with short cycle lengths are suggestive of AF substrate [58], and several studies have identified them in 
CS. The presence of CFAEs gives us a clue about arrhythmogenicity of CS and its significance that involves the evaluation of cycle length in persistent AF.

\section{Conclusion}

The CS is not only a vascular structure but rather a developmental, anatomical, and electrophysiological part of the cardiac electrical conduction system. The CS plays a major role in maintenance and recurrence of AF. This knowledge may help in the management of therapeutic choices for persistent AF ablation.

\section{Disclosure Statement}

The authors declare that they have no conflicts of interest.

\section{References}

1 Matsuyama TA, Ho SY, McCarthy KP, Ueda A, Makimoto H, Satomi K, et al. Anatomic assessment of variations in myocardial approaches to the atrioventricular node. J Cardiovasc Electrophysiol. 2012 Apr;23(4):398403.

2 Morita H, Zipes DP, Morita ST, Wu J. The role of coronary sinus musculature in the induction of atrial fibrillation. Heart Rhythm. 2012 Apr;9(4):581-9.

3 Haïssaguerre $M$, Hocini $M$, Takahashi $Y$, O'Neill MD, Pernat A, Sanders P, et al. Impact of catheter ablation of the coronary sinus on paroxysmal or persistent atrial fibrillation. J Cardiovasc Electrophysiol. 2007 Apr;18(4): 378-86.

4 Lin WS, Tai CT, Hsieh MH, Tsai CF, Lin YK, Tsao HM, et al. Catheter ablation of paroxysmal atrial fibrillation initiated by non-pulmonary vein ectopy. Circulation. 2003 Jul; 107(25):3176-83.

5 Haïssaguerre M, Sanders P, Hocini M, Takahashi Y, Rotter M, Sacher F, et al. Catheter ablation of long-lasting persistent atrial fibrillation: critical structures for termination. J Cardiovasc Electrophysiol. 2005 Nov; 16(11): 1125-37.

6 Pavin D, Boulmier D, Daubert JC, Mabo P. Permanent left atrial tachycardia: radiofrequency catheter ablation through the coronary sinus. J Cardiovasc Electrophysiol. 2002 Apr:13(4):395-8.

7 Volkmer M, Antz M, Hebe J, Kuck KH. Focal atrial tachycardia originating from the musculature of the coronary sinus. J Cardiovasc Electrophysiol. 2002 Jan;13(1):68-71.

8 Katritsis D, Ioannidis JP, Giazitzoglou E, Korovesis S, Anagnostopoulos CE, Camm AJ. Conduction delay within the coronary sinus in humans: implications for atrial arrhythmias. J Cardiovasc Electrophysiol. 2002 Sep; 13(9):859-62.

9 Eckardt L, Haverkamp W, Breithardt G. Antiarrhythmic therapy in heart failure. Heart Fail Monit. 2002;2(4):110-9.
10 Knecht S, O’Neill MD, Matsuo S, Lim KT, Arantes L, Derval N, et al. Focal arrhythmia confined within the coronary sinus and maintaining atrial fibrillation. J Cardiovasc Electrophysiol. 2007 Nov;18(11):1140-6.

11 Gaita F, Paperini L, Riccardi R, Ferraro A. Cryothermic ablation within the coronary sinus of an epicardial posterolateral pathway. J Cardiovasc Electrophysiol. 2002 Nov;13(11): 1160-3.

12 Ho SY, Sánchez-Quintana D, Becker AE. A review of the coronary venous system: a road less travelled. Heart Rhythm. 2004 May; 1(1): 107-12.

13 Ratajczyk-Pakalska E, Błoch P, Kulig A. Termination of the coronary sinus in the left atrium. Folia Morphol (Warsz). 1989;48(1-4): 151-5.

14 Silver MA, Rowley NE. The functional anatomy of the human coronary sinus. Am Heart J. 1988 May;115(5):1080-4.

15 Katritsis DG. Arrhythmogenicity of the coronary sinus. Indian Pacing Electrophysiol J. 2004 Oct; $4(4): 176-84$.

16 Ahmed N, Rungatscher A, Linardi D, Molon G, Luciani GB, Faggian G. PP-158 Coronary Sinus Can Be Target for Permanent Atrial Fibrillation Ablation Therapy? Am J Cardiol. 2016;117:S98

17 Barcelo A, De la Fuente LM, Stertzer SH. Anatomic and histologic review of the coronary sinus. Int J Morphol. 2004;22:331-338.

18 von Lüdinghausen $M$. The venous drainage of the human myocardium. Adv Anat Embryol Cell Biol. 2003;168:I-VIII.

19 Wessels A, Sedmera D. Developmental anatomy of the heart: a tale of mice and man. Physiol Genomics. 2003 Nov; 15(3):165-76.

20 Kronzon I, Tunick PA, Jortner R, Drenger B, Katz ES, Bernstein N, et al. Echocardiographic evaluation of the coronary sinus. J Am Soc Echocardiogr. 1995 Jul-Aug;8(4):518-26.

21 Chauvin M, Shah DC, Haïssaguerre M, Marcellin L, Brechenmacher C. The anatomic basis of connections between the coronary sinus musculature and the left atrium in humans. Circulation. 2000 Feb;101(6):647-52.
22 von Lüdinghausen $\mathrm{M}$, Ohmachi N, Boot C. Myocardial coverage of the coronary sinus and related veins. Clin Anat. 1992;5:1-15.

23 Tassinari CG, Munha JMU, Teixeira W, Palacios T, Nutman AP, Santos AP, et al. The imataca complex, NW amazonian craton, venezuela: crustal evolution and integration of geochronological and petrological cooling histories. Episodes. 2004;27(1):3-12.

24 Ambrose MB, Avari Silva JN, Rudokas M, Bowman TM, Murphy J, Van Hare GF. Coronary sinus morphology in pediatric patients with supraventricular tachycardia. J Interv Card Electrophysiol. 2018 Mar;51(2):163-8.

25 Justaniah A, Mckee B, Silver J, Wald C, Flacke S. Coronary sinus to left atrium communication. J Radiol Case Rep. 2013 Dec;7(12):1620.

26 Zabina B, Singla RK, Sharma RK, Bala N. Morphological and Morphometric Study of Coronary Sinus in North Indian Population. J Clin Diagn Res. 2017 Sep;11(9):AC15-9.

27 Steiner I. [A hitherto unknown priority of Jan Ev. Purkyne-myocardial sleeves of the pulmonary veins. Contribution to the pathogenesis of atrial fibrillation]. Cas Lek Cesk. 2005; 144(10):709-10.

28 Rossi LM. L. Clinico-pathological Approach to Cardiac Arrhythmias. A Color Atlas. Clinico-pathological Approach to Cardiac Arrhythmias A Color Atlas. Torino: Centro Scientifico Torinense Editore; 1990.

29 Kugler S, Nagy N, Rácz G, Tőkés AM, Dorogi B, Nemeskéri Á. Presence of cardiomyocytes exhibiting Purkinje-type morphology and prominent connexin 45 immunoreactivity in the myocardial sleeves of cardiac veins. Heart Rhythm. 2018 Feb;15(2):258-64.

30 Yoshida K, Chugh A, Good E, Crawford T, Myles J, Veerareddy S, et al. A critical decrease in dominant frequency and clinical outcome after catheter ablation of persistent atrial fibrillation. Heart Rhythm. 2010 Mar;7(3) 295-302. 
31 Makimoto $\mathrm{H}$, Zhang Q, Tilz RR, Wissner E, Cuneo A, Kuck KH, et al. Aborted sudden cardiac death due to radiofrequency ablation within the coronary sinus and subsequent total occlusion of the circumflex artery. J Cardiovasc Electrophysiol. 2013 Aug;24(8):92932.

32 Takahashi Y, Jaïs P, Hocini M, Sanders P, Rotter M, Rostock T, et al. Acute occlusion of the left circumflex coronary artery during mitral isthmus linear ablation. J Cardiovasc Electrophysiol. 2005 Oct;16(10):1104-7.

33 Traykov VB, Pap R, Shalganov TN, Bencsik G, Makai A, Gallardo R, et al. Electrogram analysis at the His bundle region and the proximal coronary sinus as a tool to predict left atrial origin of focal atrial tachycardias. Europace. 2011 Jul;13(7):1022-7.

34 Traykov VB. Mapping strategies in focal atrial tachycardias demonstrating early septal activation: distinguishing left from right. Curr Cardiol Rev. 2015;11(2):111-7.

35 Sánchez-Quintana D, López-Mínguez JR, Pizarro G, Murillo M, Cabrera JA. Triggers and anatomical substrates in the genesis and perpetuation of atrial fibrillation. Curr Cardiol Rev. 2012 Nov;8(4):310-26.

36 January CT, Wann LS, Alpert JS, Calkins H, Cigarroa JE, Cleveland JC Jr, et al.; American College of Cardiology/American Heart Association Task Force on Practice Guidelines. 2014 AHA/ACC/HRS guideline for the management of patients with atrial fibrillation: a report of the American College of Cardiology/American Heart Association Task Force on Practice Guidelines and the Heart Rhythm Society. J Am Coll Cardiol. 2014 Dec;64(21): e1-76.

37 Attanasio P, Qaiyumi D, Rohle R, Wutzler A, Safak E, Muntean B, et al. Coronary sinus signal amplitude predicts left atrial scarring. Acta Cardiol. 2017 Dec 22:1-6.

38 Wit AL, Cranefield PF. Triggered and automatic activity in the canine coronary sinus. Circ Res. 1977 Oct;41(4):434-45.

39 Wit AL. Coronary sinus electrophysiology and arrhythmogenesis: historical developments. In: Chen SA, Haïssaguerre M, Zipes DP, editors. Thoracic Vein Arrhythmogenesis: Mechanisms and Treatment. Oxford: Blackwell Futura; 2004. p. 21.

40 Nademanee K, McKenzie J, Kosar E, Schwab M, Sunsaneewitayakul B, Vasavakul T, et al. A new approach for catheter ablation of atrial fibrillation: mapping of the electrophysiologic substrate. J Am Coll Cardiol. 2004 Jun; 43(11):2044-53.

41 Oral H, Chugh A, Good E, Wimmer A, Dey S, Gadeela N, et al. Radiofrequency catheter ablation of chronic atrial fibrillation guided by complex electrograms. Circulation. 2007 May;115(20):2606-12.

42 Habib A, Lachman N, Christensen KN, Asirvatham SJ. The anatomy of the coronary sinus venous system for the cardiac electrophysiologist. Europace. 2009 Nov;11 Suppl 5:v15-21.
43 Erlanger J, Blackman JR. A study of relative rhythmicity and conductivity in various regions of the auricles of the mammalian heart. Am J Physiol. 1907;19(1):125-174.

44 Romero J, Gianni C, Di Biase L, Natale A. Catheter Ablation for Long-Standing Persistent Atrial Fibrillation. Methodist DeBakey Cardiovasc J. 2015 Apr-Jun;11(2):87-93.

45 Morita H, Zipes DP, Morita ST, Wu J. Isolation of canine coronary sinus musculature from the atria by radiofrequency catheter ablation prevents induction of atrial fibrillation. Circ Arrhythm Electrophysiol. 2014 Dec;7(6): 1181-8.

46 Haïssaguerre M, Jaïs P, Shah DC, Takahashi A, Hocini M, Quiniou G, et al. Spontaneous initiation of atrial fibrillation by ectopic beats originating in the pulmonary veins. N Engl J Med. 1998 Sep;339(10):659-66.

47 Rotter M, Sanders P, Takahashi Y, Hsu LF, Sacher F, Hocini M, et al. Images in cardiovascular medicine. Coronary sinus tachycardia driving atrial fibrillation. Circulation. 2004 Aug 10;110(6):e59-60.

48 Chugh A, Oral H, Good E, Han J, Tamirisa K, Lemola $\mathrm{K}$, et al. Catheter ablation of atypical atrial flutter and atrial tachycardia within the coronary sinus after left atrial ablation for atrial fibrillation. J Am Coll Cardiol. 2005 Jul; 46(1):83-91.

49 Yamada T, Murakami Y, Plumb VJ, Kay GN. Focal atrial fibrillation originating from the coronary sinus musculature. Heart Rhythm. 2006 Sep;3(9):1088-91.

50 Yin X, Zhao Z, Gao L, Chang D, Xiao X, Zhang R, et al. Frequency Gradient Within Coronary Sinus Predicts the Long-Term Outcome of Persistent Atrial Fibrillation Catheter Ablation. J Am Heart Assoc. 2017 Mar; 6(3):e004869.

51 Pambrun T, Denis A, Duchateau J, Sacher F, Hocini M, Jaïs P, et al. MARSHALL bundles elimination, Pulmonary veins isolation and Lines completion for ANatomical ablation of persistent atrial fibrillation: MARSHALLPLAN case series. J Cardiovasc Electrophysiol. 2019 Jan;30(1):7-15.

52 Fassini G, Riva S, Chiodelli R, Trevisi N, Berti M, Carbucicchio C, et al. Left mitral isthmus ablation associated with PV Isolation: longterm results of a prospective randomized study. J Cardiovasc Electrophysiol. 2005 Nov; 16(11):1150-6.

53 Oral H, Ozaydin M, Chugh A, Scharf C, Tada $\mathrm{H}$, Hall B, et al. Role of the coronary sinus in maintenance of atrial fibrillation. J Cardiovasc Electrophysiol. 2003 Dec;14(12):132936.

54 Mainigi SK, Sauer WH, Cooper JM, Dixit S, Gerstenfeld EP, Callans DJ, et al. Incidence and predictors of very late recurrence of atrial fibrillation after ablation. J Cardiovasc Electrophysiol. 2007 Jan;18(1):69-74.
55 Di Biase L, Santangeli P, Natale A. How to ablate long-standing persistent atrial fibrillation? Curr Opin Cardiol. 2013 Jan;28(1):2635.

56 Sanders P, Jaïs P, Hocini M, Haïssaguerre M. Electrical disconnection of the coronary sinus by radiofrequency catheter ablation to isolate a trigger of atrial fibrillation. J Cardiovasc Electrophysiol. 2004 Mar;15(3):364-8.

57 Haïssaguerre M, Hocini M, Sanders P, Takahashi Y, Rotter M, Sacher F, et al. Localized sources maintaining atrial fibrillation organized by prior ablation. Circulation. 2006 Feb; 113(5):616-25.

58 Teh AW, Kalman JM, Kistler PM, Lee G, Sutherland F, Morton JB, et al. Prevalence of fractionated electrograms in the coronary sinus: comparison between patients with persistent or paroxysmal atrial fibrillation and a control population. Heart Rhythm. 2010 Sep; 7(9):1200-4.

59 Konings KT, Smeets JL, Penn OC, Wellens HJ, Allessie MA. Configuration of unipolar atrial electrograms during electrically induced atrial fibrillation in humans. Circulation. 1997 Mar;95(5):1231-41.

60 Nair M, Nayyar S, Rajagopal S, Balachander J, Kumar M. Results of radiofrequency ablation of permanent atrial fibrillation of $>2$ years duration and left atrial size $>5 \mathrm{~cm}$ using $2-\mathrm{mm}$ irrigated tip ablation catheter and targeting areas of complex fractionated atrial electrograms. Am J Cardiol. 2009 Sep;104(5):683-8.

61 Estner HL, Hessling G, Ndrepepa G, Wu J, Reents T, Fichtner S, et al. Electrogram-guided substrate ablation with or without pulmonary vein isolation in patients with persistent atrial fibrillation. Europace. 2008 Nov; 10(11): 1281-7.

62 Forleo GB, Mantica M, De Luca L, Dello Russo A, Casella M, Santini L, et al. Impact of preexistent areas of complex fractionated atrial electrograms on outcome after pulmonary vein isolation. J Interv Card Electrophysiol. 2008 Apr;21(3):227-34.

63 Boles U, Gul EE, Enriquez A, Starr N, Haseeb $\mathrm{S}$, Abdollah H, et al. Coronary Sinus Electrograms May Predict New-onset Atrial Fibrillation After Typical Atrial Flutter Radiofrequency Ablation (CSE-AF). J Atr Fibrillation. 2018 Jun;11(1):1809-1809.

64 Anusionwu O, Calkins H. Catheter Ablation of Long Standing Persistent Atrial Fibrillation: lessons Learned. J Atr Fibrillation. 2013 Feb;5(5):680.

65 Ammar-Busch S, Reents T, Knecht S, Rostock T, Arentz T, Duytschaever M, et al. Correlation between atrial fibrillation driver locations and complex fractionated atrial electrograms in patients with persistent atrial fibrillation. Pacing Clin Electrophysiol. 2018 Oct; 41(10):1279-85.

66 Mantini E, Grondin CM, Lillehei CW, Edwards JE. (1966). Congenital Anomalies Involving the Coronary Sinus. Circulation. 1966;33(2):317-327.
CS Ablation: A Key Player Substrate in Recurrence of Persistent AF
Cardiology 2019;143:107-113

DOI: $10.1159 / 000501819$ 